\title{
Pontos de Cultura enquanto movimento social: uma pesquisa netnográfica
}

\author{
Julio César Pedroso e Carlos José Martins
}

\section{Resumo}

Tomando como ponto de partida a formação de uma rede de pontos de cultura enquanto política pública, este artigo visa investigar sua possível configuração como um movimento social. Para tanto, foi realizada uma pesquisa bibliográfica sobre teorias clássicas e contemporâneas dos movimentos sociais, de modo a tratar de forma adequada a inserção dessa problemática na especificidade do campo investigado. Ademais, foi feita uma netnografia através da inserção do pesquisador em uma lista de e-mails representativa da qual participam diversos atores culturais ligados a pontos de cultura do Estado de São Paulo. Além dessa lista foram analisados espaços presenciais de participação, formação de grupos e entrevistas com articuladores da rede. A partir das análises realizadas, pôde-se concluir que a rede dos pontos de cultura comporta um potencial significativo de catalisação de movimentos sociais em fase de expansão. Nesse processo, a cultura digital e 0 software livre possuem um papel de destaque.

\section{Palavras-chave}

Movimento social. Pontos de Cultura. Netnografia.

Julio César Pedroso I julio.pedros083@gmail.com Mestrando em Desenvolvimento Humano e Tecnologias pela Universidade Estadual Paulista - (Unesp). Bolsista da Fundação de Amparo a Pesquisa do Estado de São Paulo (Fapesp).

Carlos José Martins I c.j.martins@uol.com.br Doutor em Filosofia pela Universidade Federal do Rio de Janeiro (UFRJ). Professor do Programa de Desenvolvimento Humano e Tecnologias da Universidade Estadual Paulista (Unesp).

\section{Introdução}

Os pontos de cultura surgem no Brasil há quase uma década sob a promessa de "desesconder" a cultura brasileira. Tentando responder aos anseios dos segmentos sociais envolvidos no campo cultural foi implantado o programa de governo intitulado Programa Nacional de Cultura, Educação e Cidadania-Cultura Viva, propondo desenvolver uma nova visão, tanto do conceito de cultura quanto da relação entre o Estado e a sociedade civil, tomando como ponto de partida a formação de uma rede de pontos de cultura enquanto política pública. Nesse sentido, este artigo visa investigar a possível configuração dessa rede como movimentos sociais.

Para tanto, inicialmente fizemos algumas análises sobre o Programa Cultura Viva, no que tange às suas concepções teóricas e de organização dos atores culturais. A seguir desenvolvemos considerações sobre teorias clássicas e contemporâneas de movimentos sociais, no sentido da construção de um campo teórico apropriado ao nosso objeto de estudo. A metodologia utilizada é apresentada bem como a justificativa de seu 
emprego. 0 processo investigativo completo é detalhado, desde a teoria até a escolha do campo a ser estudado. Por fim, analisamos os dados obtidos através do material empírico e apresentamos nossas considerações finais.

\section{Programa Cultura Viva}

Quando falamos em Programa Cultura Viva, estamos falando de uma política pública concebida pelo Ministério da Cultura em 2004, que abrange muitos conceitos teóricos e procedimentos advindos de experiências práticas da sociedade brasileira. A concepção desse programa não se deu de um dia para o outro, mas sim através de todo um processo social, e cultural, que os gestores do Ministério da Cultura, comandados pelo então ministro Gilberto Gil, compartilhavam. Em seu discurso de posse como ministro da cultura, Gil conceitua o Programa Cultura Viva como uma ação voltada à cidadania cultural. Sobre isso, a pesquisadora Liliana Sousa e Silva (2007) demonstra que 0 conceito de cidadania cultural utilizado por Gil foi oriundo da política da primeira gestão pública de cultura do Partido dos Trabalhadores (1989-1992). Essa passagem se refere ao governo municipal da cidade de São Paulo, que tinha como secretária de cultura a filósofa Marilena Chaú. Ao final de sua gestão, Chauí (1992) faz um balanço no qual "apresenta uma definição de cidadania cultural elaborada a partir de experiências políticas anteriores, especialmente às de Mário de Andrade e Sábato Magaldi" (SOUSA E SILVA, 2007, p. 22).
Para Chauí, cidadania cultural significa que a cultura deve ser entendida como direito de todo cidadão, em uma definição que vai muito além das belas-artes, capturando em sua concepção toda a produção simbólica e dinâmica existente em uma sociedade. Entendendo a cultura (nessa forma alargada) como direito, o Estado passa a ter a função não de produtor cultural, mas sim de provedor de condições satisfatórias para que sejam realizados os projetos culturais da sociedade (CHAÚ, 2006).

Para os conceptores do programa a noção de vida introduz outra inflexão articulada à noção de cultura. Para estes a vida da cultura viva remete a potencialidades criadas através das experiências, sobretudo da experiência coletiva. A possibilidade dessa ocorrência é que cria as potências de vida, que são difundidas com 0 trabalho em rede: "0 Cultura Viva é concebido como uma rede orgânica de gestão, agitação, e criação cultural" (TURINO, 2009). Todo esse cultivo dinâmico de produção da vida é que englobaria a ideia de uma cultura viva.

Essa rede orgânica seria formada pelos pontos de cultura, que se constituíram como principal articulador e difusor do conceito de cultura viva. 0 fazer político naquele momento necessitava, antes de tudo, de um diagnóstico crítico do fazer cultural do Brasil. A proposta do Programa Cultura Viva é que esse processo se dê através dos pontos de cultura: grupos culturais e artísticos, pequenos ou grandes, que atuam e são reconhecidos por suas comunidades. Esses grupos recebem financiamento do governo com o objetivo de potencializar suas 
atividades. Tal potencialização significa também a expansão do fazer cultural coletivo em rede. Os pontos de cultura não têm um modelo único, nem de instalações físicas, nem de programação ou atividade. Um aspecto comum a todos é a transversalidade da cultura e a gestão compartilhada entre poder público e comunidade. (BRASIL, 2012)

\section{O Programa Cultura Viva e os pontos de cultura} têm sido foco de vários estudos acadêmicos nos últimos anos, o que sugere um alargamento do campo da análise crítica que vai muito além do discurso oficial. Para Lacerda, Marques e Rocha (2010), os pontos de cultura possuem uma dinâmica que tem na simplicidade um dos seus grandes méritos. Por outro lado, enfrentam dificuldades pela ineficiência e forte burocracia do Estado, o que é acentuado pela fragilidade da sociedade civil em conhecer as ferramentas que lhe dão acesso às estruturas públicas.

Liliana Sousa e Silva (2007) propõe a criação de indicadores culturais que são importantes para uma política pública de cultura atingir amplamente as demandas reais da sociedade. Para a pesquisadora, o Programa Cultura Viva é um importante agente de transformação não só pelas ações dos pontos de cultura, mas também porque contribui com 0 levantamento dessas demandas e indicadores, $\mathrm{e}$ consequentemente para a concepção de futuras políticas públicas que buscam resgatar a proximidade com os problemas cotidianos dos cidadãos.

Segundo Maria Cristina Brasil Magnani (2011) o Programa Cultura Viva dá ensejo a investigações para um melhor entendimento de teorias da Ciência da Informação, analisando a utilidade de um regime de informação enquanto abordagem para a compreensão da política de informação. Para a autora, "um regime de informação é sempre um espaço de disputa entre diferentes posições" (MAGNANI, 2001, p. 138). Neste sentido, o Programa Cultura Viva se presta como um fértil campo de análise, devido à sua organização em rede, 0 uso das ferramentas digitais comunicacionais, bem como as disputas postas em jogo.

Ademais, caberia mencionar a noção de cultura digital como ferramenta conceitual significativa para a problematização do acima denominado "corpo orgânico da cultura" de modo a questionar 0 estatuto de cidadania que lhe seria correlato. Como frisa o pesquisador Frederico A. Barbosa da Silva (2011), a inclusão digital deve ser discutida no âmbito dos direitos à informação. Portanto, quando analisado tal processo no caso brasileiro aqui abordado, cabe interrogar em que medida o Programa Cultura Viva se presta como estratégia pública de construção e fortalecimento das práticas culturais locais e da cidadania.

\section{Teorias dos Movimentos Sociais - a construção de um paradigma}

Os principais debates teóricos sobre os movimentos sociais nos sugerem que não há um conceito único sobre movimento social, mas 
sim vários, conforme o paradigma utilizado pelo pesquisador e no qual está inserido o objeto de estudo. Dessa forma, enfatizaremos nossas análises no paradigma latino-americano, entendendo ser esse o que abrange observações mais próximas das características de nosso objeto de estudo. Entretanto:

Falar de paradigma teórico latino-americano sobre os movimentos sociais é mais uma colocação estratégica do que real. 0 que existe é um paradigma bem diferenciado de lutas e movimentos sociais, na realidade concreta, quando comparado com os movimentos europeus, norte-americanos, canadenses etc., e não um paradigma teórico propriamente dito (GOHN, 1997, p. 211).

0 trecho acima deixa claro o contexto ao qual nos referimos quando falamos em um paradigma latino-americano. Ainda segundo Gohn (1997), nas últimas décadas do século XX houve uma grande diversidade de movimentos sociais conhecidos como contemporâneos. Os movimentos na América Latina se diferenciavam entre os novos movimentos (lutas por equipamentos coletivos em geral) e antigos movimentos populares (sociedade de bairros e outros) onde imperava práticas clientelistas. Dessa forma, a principal diferença presente nos movimentos contemporâneos é a prática política, principalmente quando se trata de relações que sempre existiram, como com a igreja, sindicatos e partidos políticos.

Em relação aos partidos políticos, Gohn (1997) destaca que esses nunca estiveram desvinculados dos movimentos sociais na América Latina, através de uma articulação política e não econômica. Essa articulação se dá pelos mesmos interesses de ação e de mudanças estruturais. Os países latino-americanos nunca tiveram Estados com tradições democráticas, e os movimentos sociais sempre possuíram a função de pressioná-los para uma abertura democrática. Nos últimos anos os governos de diversos países da América Latina têm sofrido processos de democratização, o que não significa que os movimentos deixem de pressionar para manter a participação popular. Esse novo panorama tem mudado as relações dos movimentos sociais com o Estado e com os partidos políticos.

Para Gohn (1997), os movimentos sociais sofrem grandes mudanças, a partir da década de 1990, que precisam ser consideradas. Houve um enfraquecimento de movimentos que trabalham com questões territorializadas e que não se articulavam em redes maiores. Por outro lado, os movimentos locais que tratavam de questões mais globais se fortaleceram por sua articulação em rede. Dessa forma, no geral os movimentos sociais diminuíram numericamente, mas cresceram quantitativamente, por intermédio das 0NGs e capacitações tecnológicas.

Gohn (2008) afirma que as mudanças sofridas pelos movimentos sociais na década de 1990 se intensificam no século XXI, se configurando de forma contraditória. Em muitos países os movimentos ganharam capacidade de organização, devido ao avanço da democracia. Em outros os movimentos perderam força junto à população, 
devido, sobretudo, à falta de credibilidade da sociedade civil com os políticos e de como é organizada a arena dos conflitos partidários. No Brasil houve uma fragilização dos movimentos sociais neste século, e isso pode ter se dado pela perda de autonomia, já que a principal estratégia da sociedade para responder aos movimentos sociais tem sido suas institucionalizações, seja por meio da criação de setores públicos responsáveis, seja pela criação de leis. Esse fator pode ser ou não favorável aos movimentos, dependendo de como forem os processos de criação desses órgãos jurídicos.

As análises sobre os movimentos sociais que se fundavam nas relações entre as classes e os movimentos populares, e que tinham como sujeito fundamental das transformações sociais a classe operária, reduziram-se nesse milênio. Houve uma ampliação do espectro desse sujeito, analisado agora em outras camadas além das populares. As ONGs se mostram fortes atores sociais nesse contexto, e essa mudança de foco levou muitos estudiosos a utilizarem abordagens que se preocupam com as formas de organização, participação e mobilização social. É nesse contexto contraditório atual que alguns outros autores se tornam também importantes para nosso delineamento teórico.

Christian Adel Mirza (2006), um pesquisador do Conselho Latino Americano de Ciências Sociais (CLACSO) analisou os movimentos sociais a partir dessa nova relação com a política vigente, incluindo as formas de dependência que foram construídas pelo e com os Estados Unidos. Do ponto de vista metodológico, Mirza (2006) faz grandes contribuições ao concluir que os movimentos sociais do novo milênio não se fortalecem devido a uma cultura política existente herdada do século XX, e que compromete a autonomia dos movimentos sociais. Sobre isso, Touraine (1989, p. 182) já afirmava que "a subordinação dos movimentos sociais à ação do Estado constitui a limitação mais grave de sua capacidade de ação coletiva autônoma".

\section{0 estudioso mexicano Rafael Sandoval} Alvarez (2000) analisa os aspectos políticos na constituição dos sujeitos pertencentes a movimentos sociais. Para ele, essa constituição se dá a partir do local que este ocupa no social, na política, no cultural e na representação simbólica de outros sujeitos. É um processo que se dá principalmente pelas tensões das diferenças entre os atores de um movimento. Desse modo, dentro de um grupo não há nada pré-construído ou dado, as definições da cultura política existente vão se construindo. Essa construção é, sobretudo, relacional, e ainda que existam as estruturas maiores que as ações, elas também se modificam. Um movimento social não assume uma identidade pré-construída apenas porque tem uma etnia, um gênero etc., mas sim no processo de luta no qual é formada essa identidade política.

Uma das novidades deste milênio em relação às argumentações discursivas e análises 
sobre movimentos sociais é o uso da categoria "mobilização social". Segundo a ciência política, mobilização social refere-se a ativações que provocam mudanças de comportamentos, adesão e acesso a projetos e programas sociais, e consequentemente mudança de valores (BOBBI0; MATEUCCI; PASQUINO, 1986). Na América Latina, o colombiano José Bernardo Toro (2007) desenvolveu uma metodologia para os chamados "produtores e reeditores" sociais, aqueles cidadãos atuantes em suas realidades locais que desenvolveriam processos participativos por meio de projetos mobilizantes. A metodologia se baseia no envolvimento dos produtores e reeditores com os problemas cotidianos, através das atuações em redes comunicativas, bem como da criação de fóruns e outros mecanismos de mobilização. Para Toro, o movimento surge como resultado do processo de mobilização. Não há uma análise mais aprofundada sobre as causas culturais, políticas e históricas sobre as gêneses dos problemas enfrentados por uma dada situação.

Nessa metodologia, os problemas são levantados e busca-se a mobilização de pessoas para suas resoluções. Entretanto, tal abordagem se baseia em muitos conceitos teóricos, se apoiando em concepções utilitaristas e pragmáticas.

\section{Levantamento de dados - um estudo netnográfico}

A metodologia de pesquisa adequada para 0 tratamento do campo cultural por excelência advém da Antropologia, em especial a etnografia. Nossas tendências ao uso dessa metodologia se devem, num primeiro momento, ao objeto de estudo: nada mais pertinente do que usar uma metodologia que trata da descrição de uma cultura para estudarmos uma rede de pontos de cultura. Essa por sua vez se articula em grande parte por meio das redes sociais e outros meios de comunicação digital. Tais fatos nos fizeram pensar em uma metodologia que respondesse a esses anseios, aliando elementos da etnografia com as tecnologias e a comunicação digital.

Assim como é próprio da Antropologia, uma das maneiras de se pesquisar atores sociais inseridos no imaginário virtual é através da observação. Dessa premissa, consideramos possíveis estudos no ciberespaço com a metodologia etnográfica. Todavia, as grandes questões que perpassam o desenvolvimento de reflexões nessas áreas são justamente em relação a como praticar a observação participante num espaço on-line .

A netnografia tem sido desenvolvida recentemente como uma metodologia que busca responder a essas questões. Para Braga (2007, p. 6):

A apropriação da técnica etnográfica, entretanto, suscitou-me uma questão epistemológica na direção do avanço na reflexão sobre os métodos para lidar com os objetos emergentes da internet. Em termos metodológicos, a etnografia se funda na noção de observação participante, visto ser impossível, em situações face a face, uma observação não-participante. Ora, os ambientes 
interacionais da CMC caracterizam-se pela ausência física das/os visitantes, sendo possível tornar-se 'invisível'. Sendo assim, seria possível apreender a cultura de um grupo sem participar dele, somente observando? Seria possível uma 'observação não-participante?' Parece ser impossível observar sem participar, ou seja, esta também seria uma forma de participação. Entretanto, interessa que, definitivamente, trata-se de uma participação muito peculiar, na medida em que é possível para o/a pesquisador/a tornar-se invisível, ou seja, ver sem ser visto/a, não interferindo em princípio na dinâmica da interação observada[...] É essa participação (mesmo que invisível) no grupo que irá viabilizar a apreensão de aspectos daquela cultura possibilitando a elaboração posterior de uma descrição densa, que demanda uma compreensão detaIhada dos significados compartilhados por seus membros e da rede de significação em questão.

Assim, essa transposição da observação

participante para os meios virtuais nos parece ser um dos principais pontos a ser considerado nessa metodologia. Outro ponto importante levantado pela autora é quanto à necessidade de se ter uma perspectiva etnometodológica do uso da netnografia. A etnometodologia, ao contrário do que sugere 0 termo, não se refere ao método utilizado, mas sim ao campo de observação. Foca-se assim os estudos aos conhecimentos tácitos dos indivíduos, as formas de entendimento do senso comum, as práticas cotidianas e as atividades rotineiras que forjam as condutas dos atores sociais, para assim se descobrir os "métodos" que as pessoas usam no seu cotidiano para entender a realidade que as cercam (ANDRÉ, 2003). Esse conceito é utilizado por Braga (2007) no sentido de salientar a importância do pesquisador netnógrafo em considerar as especificidades de cada campo de estudo, de cada grupo no qual está sendo aplicada a metodologia, já que "em termos metodológicos, a etnometodologia trabalha com a noção de "exigência singular de adequação", uma competência exigida do/a analista na atividade concernida" (BRAGA, 2009, p. 8).

A autora ainda nos chama atenção para um outro fator importante a ser considerado na pesquisa netnográfica: para ela, o log file - definido como um arquivo onde se registram todas as atividades realizadas por uma sessão on-line ou um programa - pode parecer uma ótima solução para captura dos dados, porém não deve ser usado como única fonte, já que estes apresentam um panorama geral do problema e "pode tirar a oportunidade do/a analista de perceber os sentidos intersubjetivamente partilhados pelo grupo em exame" (BRAGA, 2009, p. 14).

Robert Kozinets (2007) nos sugere 4 ações práticas que podem recuperar procedimentos básicos de metodologia específicos da transposição da etnografia para a netnografia: "Entrée cultural, coleta e análise dos dados, ética de pesquisa e checagem de informações com os membros do grupo ".

0 Entrée cultural é a preparação para o trabalho de campo, etapa na qual o pesquisador identifica quais aspectos pretende levantar com a pesquisa $\mathrm{e}$ seleciona em quais grupos virtuais esses aspectos poderiam ser validados e/ou compreendidos.

Para a coleta e análise, três tipos de captura são tidos como eficazes: 1) o volume de informações disponíveis pelos meios virtuais pode ser muito 
grande, o que faz com que o pesquisador necessite utilizar filtros para escolhas de informações realmente pertinentes, como captar dados diretamente dos membros das comunidades; 2) refere-se às observações do pesquisador em relação às práticas comunicacionais existentes nos grupos analisados, inclusive contando com sua própria participação; 3) dados levantados em entrevistas com pessoas participantes dos grupos, por meio de ferramentas como e-mails, chats, mensagens instantâneas etc. 0 caminho eticamente recomendável pelo autor é a identificação do pesquisador e das intenções da pesquisa a todos envolvidos, já que é muito polêmica a questão de até onde os dados presentes em uma comunidade virtual são públicos. Outra ação importante para a ética de pesquisa é tratar, na escrita textual, os participantes com pseudônimos ou nomes que não os identifiquem completamente. A checagem de informações com os membros do grupo seguem linha ética, além de acrescentar credibilidade à pesquisa.

\section{0 trabalho de campo}

A preparação para a entrada do trabalho de campo se iniciou já com os levantamentos teóricos apresentados em itens anteriores, onde identificamos aspectos que achamos necessários considerar para a avaliação da suposta rede de pontos de cultura enquanto um movimento social. Como uma das premissas do Cultura Viva é a articulação dos pontos de cultura em rede através da cultura digital, são inúmeros os grupos virtuais que poderiam nos fornecer ótimos campos de pesquisa. 0 grupo escolhido foi uma lista de e-mails chamada pontossp. A escolha dessa lista se deu basicamente por dois motivos: primeiro porque o pesquisador já possuía uma participação nessa lista há algum tempo, o que facilitaria sua observação participante e a identificação das especificidades desse grupo para possíveis adaptações e aplicações da netnografia, conforme sugere Braga (2007), além de já se ter uma certa credibilidade quanto à rede e aos autores nela presentes, como ressalta Kozinets (1997); e segundo porque achamos interessante escolher um grupo que reunisse sujeitos/agentes de uma região mais próxima para que facilitasse possíveis encontros presenciais, como foi o ocorrido.

A lista pontossp reúne e-mails de pessoas participantes da rede de pontos de cultura do Estado de São Paulo, e também por outros interessados aos movimentos culturais. Foi criada em agosto de 2007 pela Comissão Paulista de Pontos de Cultura, e hoje conta com 743 membros. ${ }^{1} 0$ pesquisador analisou todos os e-mails enviados à lista nos meses de março, abril, maio e junho de 2012. Nesse período, foram totalizados 1718 e-mails enviados à lista, o que causa o problema levantado por Kozinets (2007) quando dizia que o volume de informação pode ser muito grande. Dessa forma, e já em posse dos elementos a serem analisados, aplicamos um filtro baseado na experiência do pesquisador com o grupo, escolhendo informações estratégicas que pontuavam ações. Criamos assim um log file 
com cerca de 30 e-mails enviados durante esse período, o que já garante amplo conteúdo de análise. Gostaríamos de salientar que a aplicação desse filtro foi um processo inserido na percepção do pesquisador quanto aos sentidos intersubjetivamente partilhados pelo grupo, inclusive por ele.

Achamos necessário realizar a coleta de dados também de encontros presenciais. A partir de informativos e combinados feitos na lista de e-mails presenciamos três encontros entre pessoas e grupos participantes da rede de pontos de cultura do Estado de São Paulo:

- 0 primeiro foi uma reunião da Comissão Paulista de Pontos de Cultura (CPPC). A Comissão Paulista é formada num sistema de eleição representativa, sendo que cada macrorregião do Estado (politicamente, 0 Estado é dividido em 9 macrorregiões, sendo que uma delas é a de Campinas) elege seus representantes para a comissão Paulista. Dessa forma, entendemos que a Comissão é extremamente importante em nossos estudos, já que, além de discutir as demandas dos pontos de cultura, também reúne suas principais lideranças.

- 0 segundo foi um encontro de alguns pontos de cultura da região metropolitana de São Paulo com a Caravana Por La Vida - essa por sua vez formada por pontos de cultura de diversos países da América Latina e que estavam no Brasil para a participação na Conferência das Nações Unidas sobre Desenvolvimento Sustentável, a Rio +20.

- 0 terceiro foi a participação na formação regional dos pontos de cultura do Estado de São Paulo macrorregião de Campinas, organizada pela parceria da Comissão Paulista de Pontos de Cultura com a Secretaria de Estado da Cultura. As formações dos pontos de cultura são importantes espaços de reunião, já que todos os pontos da rede paulista participam. Nesse encontro em especial aconteceu o fórum regional, onde foram levantadas demandas, questionamentos e deliberações.

Realizamos também entrevistas para a consolidação do levantamento de dados. Foram escolhidos dois articuladores culturais que trabalham em pontos de cultura. 0 primeiro deles, chamado aqui de $\mathrm{E}$, é coordenador de um Pontão de Cultura na cidade de São Carlos SP, e há muitos anos participa dos principais debates colocados em torno da cultura no Brasil. 0 segundo, chamado aqui de E2, é articulador de projetos culturais na cidade de Rio Claro e participante ativo dos debates em torno do Programa Cultura Viva. Os dois entrevistados possuem ampla experiência com o Programa Cultura Viva, participando das esferas hierárquicas como as comissões, desde suas concepções. A escolha dos 
entrevistados se deu de forma estratégica. Primeiro pela proximidade dos dois com o pesquisador, tanto física - já que 0 entrevistador reside na cidade de Rio Claro, que também fica próxima à cidade de São Carlos -, quanto na facilidade de contatá-los - 0 pesquisador já conhecia os entrevistados através de outros encontros e eventos. Segundo porque o trabalho desempenhado pelos dois articuladores nos parece muito intrínseco ao Programa Cultura Viva e à proposta do presente trabalho. 0 Pontão de Cultura, cujo primeiro entrevistado coordena, tem o objetivo de articular ações em cultura digital com vários outros pontos de cultura, sempre buscando o trabalho em rede. 0 segundo entrevistado participa, ativamente e de forma muito ampla, dos fóruns colegiados de discussão, tanto virtuais quanto presenciais, dessa suposta rede dos pontos de cultura. Essas duas experiências se mostram fundamentais ao nosso campo de análise.

Quanto à questão ética, ressaltamos que pedimos a licença de uso dos textos escritos pela lista de e-mails e pelas palavras faladas nos encontros presenciais, que foram mais tarde transcritas. $0 \mathrm{~s}$ nomes e os e-mails dos membros do grupo não são mostrados de modo que se possa identificá-los, bem como o nome dos entrevistados, que são nesse trabalho identificados pelos codinomes E1 e E2.

\section{Análise dos dados obtidos}

Percebemos que é complicado pensarmos nos pontos de cultura como um único grande coletivo. Uma das propostas do Programa é a formação de uma rede de pontos de cultura, porém não conseguimos identificar essa grande rede formada, seja de forma ideológica, acionista ou até mesmo virtual. Não existe sequer uma grande lista de e-mails ou espaço virtual de debate da qual participem todos os pontos de cultura, esse espaço nunca foi criado, como descreve 0 entrevistado E2:

Mesmo se falando tanto do movimento de cultura digital, nunca foi criada, seja pelo governo, por alguns grupos, ou por quem quer que seja, um espaço de comunicação que incluísse todos os pontos de cultura do país.

Essa primeira aproximação da atual configuração dos grupos que são pontos de cultura requer algumas reflexões. Uma delas se deve ao processo de como um grupo se torna ponto de cultura e passa a fazer parte dessa nossa análise. Isso ocorre através de um edital público, aberto pelo governo. Existem três modelos possíveis de editais: os gestados pelo Ministério da Cultura, os gestados pelos Estados e os gestados pelos municípios. Os dois últimos modelos formam as denominadas redes estaduais e redes municipais de pontos de cultura. Através dos editais públicos, os grupos podem escrever e inscrever seus projetos, pleiteando se tornarem um ponto de cultura. Para isso é necessário que o grupo seja constituído juridicamente, e obedeça a algumas regras estabelecidas no edital. A partir do momento que um grupo (entidade) se torna ponto de cultura, passa a seguir um regime estabelecido pela lei que normatiza o repasse de verba pública para a sociedade civil. 
Existe uma compreensão de que o sistema de editais é justo e democrático, já que possibilita qualquer grupo pleitear tal chancela, porém, quando pensado como um todo isso causa algumas divergências. Os grupos que se tornam pontos de cultura nem sempre compartilham as mesmas ideologias, o que dificulta ou impossibilita a participação de todos os grupos em uma mesma rede. É nesse ponto que identificamos uma característica importante observada sobre os pontos de cultura: existem formadas e consolidadas várias pequenas redes, que funcionam muito bem devido às afinidades que os grupos encontram entre si, sejam elas afinidades geográficas, ideológicas, por linguagens artísticas ou até mesmo afinidades pessoais das lideranças dos grupos.

A rede de $e$-mails analisada é um exemplo disso. Apesar da proposta da formação da rede de e-mails pontossp ser reunir todos os pontos de cultura do Estado de São Paulo, apenas algumas pessoas representantes de alguns grupos participam efetivamente. Entendemos que a participação na rede se deve mesmo pelas questões de afinidade entre os grupos e com a CPPC. Isso porque, analisando os e-mails presentes em nosso log file, vemos que a maioria dos articuladores dessa rede são os representantes que formam a CPPC.

Esses articuladores reconhecem essa pequena rede como um movimento, e se autodenominam como tal, como pode ser observado em vários e-mails:
....São Paulo e demais estados vai fortalecendo o movimento dos Pontos de Cultura e certamente o Programa Cultura Viva!

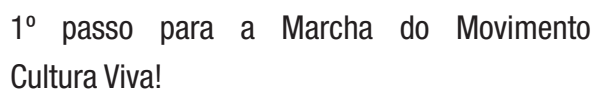
vimento de Pontos de Cultura no dia 14 de abril.

Porém, podemos também entender um pouco do que essa rede compreende por movimento:

Convidamos os Pontos para participarem de reunião para discutir a possibilidade de formação da Federação Paulista dos Pontos de Cultura, será no dia 26 de Maio ás 15 horas na sede do Pontão de Cultura da Vila Prudente, Rua Baia Grande $n^{\circ} 456$, Vila Prudente ,São Paulo,Capital.

Agora sim.

Com Estatuto - CNPJ - e assim representatividade?

Sim, também acho, por isto discuti bastante por aqui a ideia de se criar um MPC - Movimento dos Pontos de Cultura. Federação é complicado, tem que haver a criação, primeiro, dos sindicatos, para depois existir a FEDERAÇÃO. Além do mais, não é barato se criar uma FEDERAÇÃO, pois depende de Carta Sindical, etc.

E porque não - já sem hora - Associação Nacional do Pontos de Cultura?

Uma Associação configurada como OSCIP (ainda que - em minha modesta opinião - a ideia de Movimento seja mais coerente com os princípios do Programa).

Verificamos que há a ideia de criação de movimento através de uma formalização, e uma 
tentativa de mobilização para que isso aconteça, se enquadrando na categoria de mobilização social pensada por Toro (2007), e discutida nas teorias sobre movimentos sociais. Há também um movimento de captura do Estado dessa mobilização social. Através dos editais públicos há uma tentativa de organização e controle do movimento cultural brasileiro. Um dos princípios do Programa Cultura Viva é a gestão compartilhada, entretanto essa diretriz favoreceu diversos conflitos, muito bem representados pelo depoimento do entrevistado E1:

o Programa foi criado em um momento no qual não existia, e nem sei se hoje existe, um reconhecimento por parte do campo cultural - dizendo aí produtores culturais, artistas, de uma maneira geral no Brasil - como um grupo de interesses comuns, determinado assim como uma classe ou algo do tipo. Então, não existindo isso, o conceito que era muito bom encontra um problema significativo que é a ideia da gestão compartilhada. Quando se fala de gestão compartilhada, se fala de compartilhar a gestão entre o governo - que é 0 detentor da gestão - e 0 outro, que é 0 alguém. Mas que alguém que é esse?

A gestão compartilhada é um princípio solidarizado e defendido pelos pontos de cultura, porém na prática essa relação se torna indefinida, já que não há uma determinação de um "outro lado" dessa gestão. 0 que acontece então muitas vezes são relações de proximidade com determinados grupos e pessoas, o que ocasiona a impressão de certos favorecimentos. É nesse ponto que introduzimos outra importante observação: a forte influência dos partidos políticos.
Os depoimentos dos entrevistados convergem em muitos pontos, e um deles é em relação à cooptação das estruturas de poder montadas sobre o Programa Cultura Viva com os partidos políticos. Segundo eles, a hierarquização das tomadas de decisão, quando se trata da sociedade civil (os grupos pontos de cultura) se deu através da montagem de comissões (nacionais e estaduais). Esse modelo propicia a disputa de espaços e poder, e teria sido estruturado já com essa finalidade. Nesse contexto, os partidos políticos da base governista teriam grande influência, e acabariam por disputar esses espaços já na concepção dessas diretrizes.

Nas reuniões presenciais pudemos observar 0 quanto os partidos políticos estão presentes nessas tomadas de decisão. Na reunião visitada da CPPC havia alguns membros partidários que anunciaram relações com alguns políticos. Isso não causou nenhuma tensão na reunião, o que nos faz pensar que dentro da Comissão haja uma identificação às ideologias partidárias. Porém, nem todos os pontos de cultura compartilham, como observamos no Encontro de Formação dos Pontos de Cultura do Estado de São Paulo ocorrido em Americana.

Esse Encontro de Formação traz elementos muito interessantes para nossa análise. Primeiro porque a rede estadual dos Pontos de Cultura de São Paulo é gestada pelo Governo Estadual através da Secretaria de Estado de Cultura (SEC), oposição clara ao Governo 
Federal. Segundo porque a SEC "obriga" todos os pontos de cultura a participarem dessas formações. A participação de todos os pontos de cultura - são mais de 500 pontos no Estado de São Paulo - causa um certo estranhamento entre os grupos ali presentes. Para fins didáticos, classificamos as atuações dos grupos nesse encontro em algumas categorias.

A primeira delas é formada pelos grupos que se identificam com as ideologias progressistas, e se aproximam de partidos que se autodenominam de esquerda e centroesquerda, da base do Governo Federal. Isso não quer dizer que todos sejam de partido, mas há uma aproximação das lutas por defesa de alguns interesses, como a demanda dos movimentos sociais, a crença na participação popular e na democracia participativa.

A segunda é formada pelos grupos que se identificam com o governo estadual, e que acreditam que é preciso que haja uma formação superior aos pontos. É nesse sentido que 0 encontro foi organizado de forma vertical (apesar do discurso ser outro). Isso ficou claro quando observamos as atividades presentes na formação, e tão bem descritas pelo entrevistado E2:

Um exemplo são os encontros de formação, nos quais o governo do estado sempre chamou outras pessoas detentoras de conhecimento e sabedoria para ensinar aos Pontos de Cultura. Não que não haja nada para os Pontos aprenderem, muito pelo contrário, sempre há muito, como por exemplo a capacitação em captação de recursos. Porém, os grupos culturais também possuem suas especialidades e conhecimentos profundos. 0 que poderia ser uma valorização desses, sempre se tornava uma aula com um professor de fora. 0 que houve de formação foi na área de conhecimento dos próprios pontos, por exemplo, a vinda de um 'outro alguém' para falar sobre culturas tradicionais, enquanto há Pontos de Cultura que há mais de cinquenta anos trabalham com cultura tradicional.

Uma terceira categoria é formada por aqueles grupos que não se interessam pelas disputas políticas, e que claramente estavam ali cumprindo seu papel enquanto gestor do dinheiro público.

Segundo o entrevistado E1:

Entendemos que os editais geram esse tipo de problema. Em um primeiro momento, quem acessa os editais são os grupos já engajados. Porém, se pensando em política pública e expansão dos direitos, a ideia é que se possa impactar toda a sociedade brasileira com Pontos de Cultura. Desse modo, as diretrizes dessa política visam o aumento do número de grupos, o que insere na disputa pelos editais os grupos menos engajados e que possuem diferentes modos operantes, como por exemplo grupos que trabalham com uma estrutura interna em que todo mundo é contratado em formato CLT, e que tem os cargos definidos de direção, e etc. É uma cara de trabalho que não é exatamente essa cara do grupo que busca por autonomia, que faz as discussões coletivas, que define como vai tomar os rumos. É outro formato. Alguns desses grupos até conseguem desempenhar um bom papel dentro da rede, e se contagiar um pouco com essa discussão que a rede traz, mas uma parte deles não. Apenas concorrem aos editais, são contemplados, usam o dinheiro público de maneira devida e conforme o plano de trabalho inicial, e mandam seus relatórios.

Essa diferença de posicionamento político gerou tensões durante 0 Encontro de Formação que 
foram observadas em vários momentos. Um deles foi o Fórum que ocorreu como última atividade do Encontro, momento no qual muitos grupos foram embora e não se interessaram em participar. Dos grupos que ficaram, muitos desistiram e foram embora no meio das discussões. Por fim, ficaram os grupos encaixados na primeira categoria descrita acima. As discussões do Fórum foram articuladas pelos membros da CPPC.

No entanto, há alguns temas que se tornam mobilizantes de toda a rede dos pontos de cultura. 0 cenário cultural que o Programa Cultura Viva propõe é unanimidade entre os grupos, $\mathrm{e}$ todos concordam que é importante essa política pública se tornar uma lei. Juntamente com essa discussão, a necessidade da mudança da lei de repasse de verba pública para a sociedade civil (Lei n. 8666) também se tornou uma bandeira comum entre os grupos. As questões financeiras se tornam centrais em todos os momentos de nossas observações. Em 2012, o repasse de verba anual feito aos grupos atrasou, o que fez com que, no período de nossa observação da lista de $e$-mails pontossp, as principais discussões se dessem em torno dessa problemática econômica. Concluímos desse contexto que os grupos chancelados como pontos de cultura entendem o financiamento da cultura como garantia constitucional. Nesses moldes, os grupos devem ser financiados pelo Estado. Outro consenso existente na rede como um todo é que a política pública pontos de cultura deve ser da sociedade civil, a fim de garantir a autonomia em relação ao governo. Essa diretriz é um sinal de que, consciente ou inconscientemente, a rede percebe um potencial movimento.

É interessante ressaltarmos que essas definições transversais, que aqui são tratadas como consensuais a toda a rede dos pontos de cultura, se constroem. De maneira geral, elas transcendem as estruturas hierárquicas montadas sobre 0 Programa, já que não foi decisão de nenhuma comissão que essas "bandeiras" fossem levantadas pelo coletivo. Em relação a isso, o entrevistado E1 nos diz como isso acontece:

Por conexão de rede mesmo. Pelo que se conversa pessoalmente, do que se conversa por e-mail, do que se conversa via redes sociais, e esse é um processo que se consolida de uma forma diferente do que é a estrutura clássica de comissão, representante, região, etc. É um outro formato, e que talvez vá caber um outro entendimento mais contemporâneo do que é um movimento social.

\section{Considerações finais}

Os pontos de cultura se organizam em grandes redes institucionalizantes, seguindo a tendência apontada por Gohn (1997) dos movimentos sociais a partir da década de 1990. A inclinação de cooptação por parte dos aparelhos estatais também ocorre na rede dos pontos de cultura. Muitas das lideranças militantes da área cultural foram contratadas pelo Estado para exercer funções gestoras de políticas públicas. Como destaca Gohn (2008), por um lado isso pode fortalecer políticas públicas que favorecem as ações populares, mas por outro pode enfraquecer 
a mobilização de um possível movimento social mais amplificado e enfático.

A forte relação da rede com os partidos políticos e 0 aparelhamento governamental presente na mesma devido à sua própria formação a partir de uma política de governo, juntamente com as formas hierarquizadas de representatividade e as formas de tomadas de decisão lembram a cultura política de dependência referida acima por Mirza (2006). Esses fatores nos parecem ser decisivos para que a rede dos pontos de cultura ainda não seja de fato um movimento social autônomo, fato apontado por Touraine (1989) como uma grave limitação de sua capacidade de ação coletiva.

Entretanto, as observações de Alvarez (2000) sobre a constituição de uma identidade política dentro de um movimento se mostra bastante interessante neste aspecto. Considerando a grande rede nacional de pontos de cultura, de uma forma geral, há uma grande diferença identitária entre os grupos, e consequentemente entre os sujeitos atores do processo cultural. As tensões criadas por essas diferenças é que podem constituir um futuro movimento social, e mesmo que existam estruturas maiores que as ações - como o Estado, essas também podem se modificar: ficou claro que o Programa Cultura Viva teve que modificar o modo de repasse de verba pública a grupos culturais, e essa mudança tende a continuar com as discussões da rede sobre a Lei n. 8666 e a aprovação da Lei Cultura Viva.
Consideramos que apesar da falta de afinidade entre alguns grupos, existe em todo esse processo pequenas redes em gestação. Tais redes dão base e suporte para a existência de uma potência de formação de movimentos sociais com maior abrangência, sobretudo quando verificada a importância do uso das ferramentas digitais na articulação dos grupos. Assim, a cultura digital e 0 software livre jogam seu papel decisivo, possibilitando outras formas de organização política, criando-se assim formas transversais através de alianças entre os diferentes grupos. São nessas dinâmicas emergentes de organização existentes na rede dos pontos de cultura que percebemos uma potência de transformação, seja dos movimentos em si, seja da sociedade como um todo.

\section{Referências}

ALVAREZ, Rafael Sandoval. La dimension política de la identidad del sujeto. Espiral, México, n. 17, p. 71-86, jan./abr. 2000.

\section{AMARAL, Adriana; NATAL, Geórgia; VIANA,} Lucina. Netnografia como aporte metodológico da pesquisa em comunicação digital.

FAMECOS, Porto Alegre, n. 20, dez. 2008.

Disponível em < http://revistaseletronicas. pucrs.br/ojs/index.php/famecos/article/ viewFile/4829/3687 > . Acesso em: 21 jan. 2013.

ANDRÉ, Marli. Etnografia da prática escolar. Campinas, SP: Papirus, 2003. 
BRAGA, Adriana. Usos e consumos de meios digitais entre participantes de weblogs: uma proposta metodológica. In: ENCONTRO DA COMPÓS, 16., 2007. Curitiba. Anais... Curitiba: UTP, 2007.

BRASIL. Ministério da Cultura. Programa Nacional de Arte, Educação, Cidadania e Economia Solidária - Cultura Viva.

3.ed. Brasília, 2008. Disponível em: < http:// www.cultura.gov.br/culturaviva/wp-content/ uploads/2010/11/Cat\%C3\%A1logo_-Cultura_Viva-2005.pdf>. Acesso em: 25 jun. 2012. BOBBIO, N.; MATTEUCCI, H.; PASQUINO, G. Dicionário de política. Brasília: Ed. UnB, 1982.

BURGWAL, G. An Introduction to the Literature on Urban Movements in Latin America. In: ASSIES, W.; BURGWAL, G.; SALMAN, T. Structures of Power, Movements of Resistance. Amsterdam: CEDLA, 1990.

CHAUÍ, Marilena. Cidadania cultural: 0 direito à cultura. São Paulo: Fundação Perseu Abramo, 2006.

GOHN, M. Da G. Teoria dos Movimentos Sociais: paradigmas clássicos e contemporâneos. São Paulo: Loyola, 1997.

\section{. História dos Movimentos e Lutas}

Sociais: a construção da cidadania dos brasileiros. São Paulo: Loyola, 1995.

. Novas teorias dos movimentos sociais. São Paulo: Loyola, 2008.
KOZINETS, Robert. The Field Behind the

Screen: Using Netnography for Marketing

Research in Online Communities. 2002. Netnography 2.0. In: BELK, R. W. Handbook of Qualitative Research Methods in Marketing. Edward Elgar Publishing, 2007.

LACERDA, Alice P.; MARQUES, Carolina C.; ROCHA, Sophia C. Programa Cultura Viva: uma nova política do Ministério da Cultura. In: RUBIM, Antônio A. C. (Org.). Políticas culturais no governo Lula. Salvador: EDUFBA, 2010.

MAGNANI, M. C. B. Política de informação: 0 Programa Cultura Viva do Ministério da Cultura. 2011. 149 f. Dissertação (Mestrado em Ciência da Informação) - Escola de Ciência Informação da Universidade Federal Minas Gerais, Minas Gerais. 2011.

MIRZA, Christian Adel. Movimientos sociales y partidos políticos em América Latina. Buenos Aires: Clacso, 2006.

SILVA, Frederico A. B. Cultura Viva e o digital. In: SILVA, Frederico A. B.; CALABRE, Lia (Org.). Pontos de cultura: olhares sobre o Programa Cultura Viva. Brasília: Ipea, 2011.

\section{SOUSA E SILVA, Liliana. Indicadores para} políticas culturais de proximidade: 0 caso Prêmio Cultura Viva. 2007. 251 f. Tese (Doutorado em Ciência da Informação) - Escola 
de Comunicações e Artes da Universidade de São

Paulo, São Paulo, 2007.

TORO, José Bernardo; WERNECK, Nísia M. D.

F. Mobilização social: um modo de construir

a democracia e a participação. Belo Horizonte:

Autêntica, 2007.

TOURAINE, Alain. Palavra e sangue. Campinas:

Ed. Unicamp, 1989.

TURINO, Célio. Ponto de Cultura: o Brasil de

baixo para cima. São Paulo: Anita Garibaldi, 2009. 
Points of Culture as

a social movement: a nethnographic research

\section{Puntos de Cultura como un movimiento social: un estudio netnográfico}

\section{Abstract}

Using as a starting point the creation of a network of Cultural Spots as a public politics, this article aims to investigate the possible configuration of it as a social movement. To do so, it has been realized a bibliographic research on classical and contemporary theories about social movements, in order to address adequately the inclusion of this issue in the specific field of investigation. Moreover, it has been done a netnography through the insertion of the researcher's e-mail into a representative list in which participate several cultural actors tied to Points of Culture of the state São Paulo. Beyond this list it has been analyzed forums, encounters, meetings, groups and interviews with network articulators. From the analysis made, can be concluded that the network of the Culture Spots sustain a significant potential to catalyze expanding social movements. In this process, the digital culture and the free software play a prominent role.

\section{Keywords}

Social Movement. Points of Culture. Netnography.

\section{Resumen}

Tomando como punto de partida para la formación de una red de Puntos de Cultura como una política pública, este artículo tiene como objetivo investigar la posible configuración de este como un movimiento social. Por lo tanto, se realizó una búsqueda bibliográfica en las teorías clásicas y contemporáneas de los movimientos sociales, con el fin de abordar de forma adecuada la inclusión de este tema en el campo específico de la investigación. Por otra parte, hubo una netnografía mediante la inserción de los investigadores en una lista de e-mails representante de los cuales participan varios actores vinculados a los puntos culturales de Cultura del Estado de São Paulo. Además de esta lista fueron analizados en el aula espacios de participación para los grupos de capacitación, y entrevistas con los organizadores de la red. A partir de los análisis, se concluyó que los puntos de la red de la Cultura tiene un gran potencial para catalizar movimientos sociales en la fase de expansión. En este proceso, la cultura Digital y el Software Livre, cumplem un papel destacado.

\section{Palabras-clave}

Movimiento social. Puntos de Cultura. Netnografia. 


\section{Expediente}

A revista E-Compós é a publicação científica em formato eletrônico da Associação Nacional dos Programas de Pós-Graduação em Comunicação (Compós). Lançada em 2004, tem como principal finalidade difundir a produção acadêmica de pesquisadores da área de Comunicação, inseridos em instituições do Brasil e do exterior.

\section{E-COMPÓS I www.e-compos.org.br I E-ISSN 1808-2599}

Revista da Associação Nacional dos Programas

de Pós-Graduação em Comunicacão.

Brasília, v.16, n.2, maio/ago. 2013

A identificação das edições, a partir de 2008

passa a ser volume anual com três números.

\section{CONSELHO EDITORIAL}

Afonso Albuquerque, Universidade Federal Fluminense, Brasil Alberto Carlos Augusto Klein, Universidade Estadual de Londrina, Brasil Alex Fernando Teixeira Primo, Universidade Federal do Rio Grande do Sul, Brasil Ana Carolina Damboriarena Escosteguy, Pontifícia Universidade Católica do Rio Grande do Sul, Brasi

Ana Gruszynski, Universidade Federal do Rio Grande do Sul, Brasil Ana Silvia Lopes Davi Médola, Universidade Estadual Paulista, Brasil André Luiz Martins Lemos, Universidade Federal da Bahia, Brasil Ângela Freire Prysthon, Universidade Federal de Pernambuco, Brasil Antônio Fausto Neto, Universidade do Vale do Rio dos Sinos, Brasil Antonio Carlos Hohlfeldt, Pontifícia Universidade Católica do Rio Grande do Sul, Brasil Antonio Roberto Chiachiri Filho, Faculdade Cásper Líbero, Brasil Arlindo Ribeiro Machado, Universidade de São Paulo, Brasil Arthur Autran Franco de Sá Neto, Universidade Federal de São Carlos, Brasil Benjamim Picado, Universidade Federal Fluminense, Brasil

César Geraldo Guimarães, Universidade Federal de Minas Gerais, Brasil Cristiane Freitas Gutfreind, Pontifícia Universidade Católica do Rio Grande do Sul, Brasil Denilson Lopes, Universidade Federal do Rio de Janeiro, Brasi Denize Correa Araujo, Universidade Tuiuti do Paraná, Brasil Edilson Cazeloto, Universidade Paulista , Brasi Eduardo Peñuela Cañizal, Universidade Paulista, Brasil Eduardo Vicente, Universidade de São Paulo, Brasil Eneus Trindade, Universidade de São Paulo, Brasi Erick Felinto de Oliveira, Universidade do Estado do Rio de Janeiro, Brasi Florence Dravet, Universidade Católica de Brasilia, Brasil Francisco Eduardo Menezes Martins, Universidade Tuiuti do Paraná, Brasil Gelson Santana, Universidade Anhembi/Morumbi, Brasil Gilson Vieira Monteiro, Universidade Federal do Amazonas, Brasil Gislene da Silva, Universidade Federal de Santa Catarina, Brasil Guillermo Orozco Gómez, Universidad de Guadalajara

Gustavo Daudt Fischer, Universidade do Vale do Rio dos Sinos, Brasil Hector Ospina, Universidad de Manizales, Colômbia

Herom Vargas, Universidade Municipal de São Caetano do Sul, Brasi leda Tucherman, Universidade Federal do Rio de Janeiro, Brasil Inês Vitorino, Universidade Federal do Ceará, Brasil Janice Caiafa, Universidade Federal do Rio de Janeiro, Brasil Jay David Bolter, Georgia Institute of Technology Jeder Silveira Janotti Junior, Universidade Federal de Pernambuco, Brasil João Freire Filho, Universidade Federal do Rio de Janeiro, Brasil John DH Downing, University of Texas at Austin, Estados Unidos
José Afonso da Silva Junior, Universidade Federal de Pernambuco, Brasi José Carlos Rodrigues, Pontifícia Universidade Católica do Rio de Janeiro, Brasi José Luiz Aidar Prado, Pontifícia Universidade Católica de São Paulo, Brasil José Luiz Warren Jardim Gomes Braga, Universidade do Vale do Rio dos Sinos, Brasil Juremir Machado da Silva, Pontifícia Universidade Católica do Rio Grande do Sul, Brasil Laan Mendes Barros, Universidade Metodista de São Paulo, Brasil Lance Strate, Fordham University, USA, Estados Unidos Lorraine Leu, University of Bristol, Grã-Bretanha Lucia Leão, Pontifícia Universidade Católica de São Paulo, Brasil Luciana Panke, Universidade Federal do Paraná, Brasil Luiz Claudio Martino, Universidade de Brasília, Brasil Malena Segura Contrera, Universidade Paulista, Brasil Márcio de Vasconcellos Serelle, Pontifícia Universidade Católica de Minas Gerais, Brasil Maria Aparecida Baccega, Universidade de São Paulo e Escola Superior de Propaganda e Marketing, Brasil

Maria das Graças Pinto Coelho, Universidade Federal do Rio Grande do Norte, Brasil Maria Immacolata Vassallo de Lopes, Universidade de São Paulo, Brasil Maria Luiza Martins de Mendonça, Universidade Federal de Goiás, Brasi Mauro de Souza Ventura, Universidade Estadual Paulista, Brasil

Mauro Pereira Porto, Tulane University, Estados Unidos Nilda Aparecida Jacks, Universidade Federal do Rio Grande do Sul, Brasi Paulo Roberto Gibaldi Vaz, Universidade Federal do Rio de Janeiro, Brasi Potiguara Mendes Silveira Jr, Universidade Federal de Juiz de Fora, Brasi Renato Cordeiro Gomes, Pontifícia Universidade Católica do Rio de Janeiro, Brasil Robert K Logan, University of Toronto, Canadá

Ronaldo George Helal, Universidade do Estado do Rio de Janeiro, Brasil Rosana de Lima Soares, Universidade de São Paulo, Brasi Rose Melo Rocha, Escola Superior de Propaganda e Marketing, Brasil Rossana Reguillo, Instituto de Estudos Superiores do Ocidente, Mexico Rousiley Celi Moreira Maia, Universidade Federal de Minas Gerais, Brasi Sebastião Carlos de Morais Squirra, Universidade Metodista de São Paulo, Brasil Sebastião Guilherme Albano da Costa, Universidade Federal do Rio Grande do Norte, Brasil

Simone Maria Andrade Pereira de Sá, Universidade Federal Fluminense, Brasi Tiago Quiroga Fausto Neto, Universidade de Brasília, Brasil Suzete Venturelli, Universidade de Brasília, Brasil Valério Cruz Brittos, Universidade do Vale do Rio dos Sinos, Brasil Valerio Fuenzalida Fernández, Puc-Chile, Chile

Veneza Mayora Ronsini, Universidade Federal de Santa Maria, Brasi Vera Regina Veiga França, Universidade Federal de Minas Gerais, Brasil

\section{COMISSÃO EDITORIAL}

Adriana Braga I Pontifícia Universidade Católica do Rio de Janeiro, Brasi

Felipe Costa Trotta I Universidade Federal Fluminense, Brasi CONSULTORES AD HOC

Alexandre Barbalho, Universidade Estadual do Ceará, Brasil

Ana Carolina Escosteguy, Pontifícia Universidade Católica do Rio Grande do Sul, Brasi

Ana Gruszynski, Universidade Federal do Rio Grande do Sul, Brasi

Arthur Ituassu, Pontifícia Universidade Católica do Rio de Janeiro, Brasil

Claudia Lahni, Universidade Federal de Juiz de Fora, Brasil

Francisco Paulo Jamil Marques, Universidade Federal do Ceará, Brasil

Jiani Bonin, Universidade do Vale do Rio dos Sinos, Brasil

José Luiz Braga, Universidade do Vale do Rio dos Sinos, Brasil

Leonel Aguiar, Pontifícia Universidade Católica do Rio de Janeiro, Brasil

Luciana Panke, Universidade Federal do Paraná, Brasil

Marcelo Kischinhevsky, Universidade do Estado do Rio de Janeiro, Brasil

Raquel Paiva, Universidade Federal do Rio de Janeiro, Brasil

Sandra Rubia da Silva, Universidade Federal de Santa Maria, Brasil

EDIČ̃̃ DE TEXTO E RESUMOS I Susane Barros

SECRETÁRIA EXECUTIVA I Juliana Depiné

EDITORAÇ̃̃o ELETRÔNICA I Roka Estúdio

TRADUÇÃO I Sieni Campos
COMPós I www.compos.org.br

Associação Nacional dos Programas de Pós-Graduação em Comunicação

Presidente

Eduardo Morettin

Universidade de São Paulo, Brasil

eduardomorettin@usp.br

Vice-presidente

Inês Vitorino

Universidade Federal do Ceará, Brasil

ines@ufc.br

Secretária-Geral

Gislene da Silva

Universidade Federal de Santa Catarina, Brasil

gislenedasilva@gmail.com 